Volume 9, No.1.4, 2020

International Journal of Advanced Trends in Computer Science and Engineering

Available Online at http://www.warse.org/IJATCSE/static/pdf/file/ijatcse2391.42020.pdf

https://doi.org/10.30534/ijatcse/2020/2391.42020

\title{
Characterization of Rain Attenuation Statistics for 5G Communication System in the Equatorial Region
}

\author{
Shi Jie Seah ${ }^{1}$, Siat Ling Jong ${ }^{2}$, Hong Yin Lam ${ }^{3}$ \\ ${ }^{1}$ Department of Electronic Engineering, Faculty of Electrical and Electronic Engineering, Universiti Tun Hussein \\ Onn Malaysia, 86400 Parit Raja, Batu Pahat, Johor, Malaysia, ssj_seah1994@ hotmail.com \\ ${ }^{2}$ Wireless and Radio Science Centre, Faculty of Electrical and Electronic Engineering, Universiti Tun Hussein \\ Onn Malaysia, 86400 Parit Raja, Batu Pahat, Johor, Malaysia, sljong@uthm.edu.my \\ ${ }^{3}$ Faculty of Engineering Technology, Universiti Tun Hussein Onn Malaysia, 84600 Hub Pendidikan Tinggi \\ Pagoh, Km 1, Jalan Panchor, Johor, Malaysia, hylam@uthm.edu.my
}

\begin{abstract}
The increasing demand for high data rates in the current communication system leads to the evolution of $5 \mathrm{G}$ technology. Therefore, it is of great interest to study the impact of path length and frequency for the $5 \mathrm{G}$ network. This paper presents the rain attenuation statistics for the $5 \mathrm{G}$ communication system in heavy rain regions using rainfall data collected over three years in Kuala Lumpur. From the analysis, the rain attenuation for a $0.2 \mathrm{~km} 5 \mathrm{G}$ terrestrial path link is less than $5 \mathrm{~dB}$. Furthermore, it is found that monthly statistics are more significant and the analysis indicates that inter-monsoon season records the highest attenuation followed by northeast and southwest seasons. In addition, the predicted statistical result using the Synthetic Storm Technique and ITU-R model provides crucial information for future $5 \mathrm{G}$ architectural planning, as well as the network operators who plan to operate their services in this particular equatorial region.
\end{abstract}

Key words : 5G, ITU-R model, Rain attenuation, SST model, Terrestrial link.

\section{INTRODUCTION}

The emergence of advanced and new mobile handsets technologies especially the need for internet access on almost entire applications causing network congestion at a lower frequency spectrum. The continuous and increasing demands of consumers have brought to the launching of 5G technology. Development of 5G technology targets to increase bandwidth, improve spectral efficiency as well as the ability to support high data rates and more devices effectively [1], [2]. 5G technology especially the 5G Long Term Evolution Advanced (LTE-A) is certainly an enhancement and good technology in Internet of Things (IoT) applications that has been expanded in many areas like transportation, smart city healthcare, industrial and electricity [3], [4]. Nevertheless, the 5G radio links that operating at a frequency higher than $10 \mathrm{GHz}$ might be affected by the atmospheric phenomenon, particularly rain. In tropical regions, the rain intensity is high, and it often happens because rainfall is a common phenomenon in this region [5]. For the terrestrial line-of-sight link, a transmission path is set up between the transmitter and receiver, as shown in Figure 1. Raindrops are absorbed and scattered by the electromagnetic waves and lead to signal attenuation. Besides, the impact of frequency and path length are also significant for the 5G network [6], and this will further discuss in the later section. The real measurement work presented in [7] shows that 28 and $38 \mathrm{GHz}$ are the frequencies that can be used for the $5 \mathrm{G}$ network.

In this paper, the study aims to characterize the rain attenuation statistics for the 5G communication system in equatorial Malaysia. The rain attenuation was predicted using ITU-R P.530-17 [8] model and Synthetic Storm Technique (SST) [9].
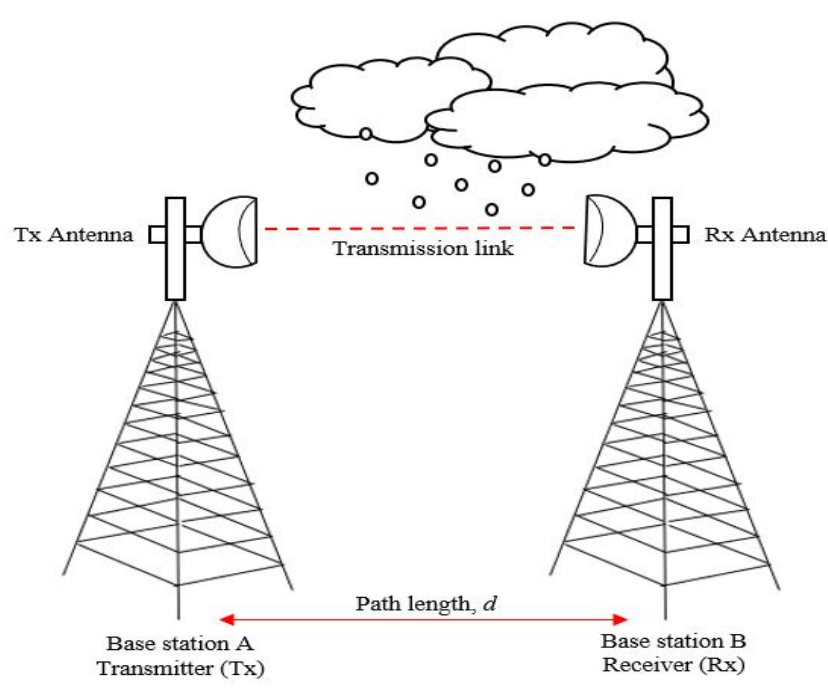

Figure 1: Scenario of terrestrial link during rainfall 
Shi Jie Seah et al., International Journal of Advanced Trends in Computer Science and Engineering, 9(1.4), 2020, 157- 162

The structure of the paper is as follows. The prediction models are briefly discussed in Section 2 and the data processing of the rainfall rates is presented in Section 3. Section 4 summarised the statistical results and discussion of the predicted rain attenuation. Finally, conclusions are drawn in Section 5.

\section{RAIN ATTENUATION PREDICTION MODEL}

ITU-R model is a well-known and widely used prediction model of all the existing rain attenuation prediction models in the communication link. ITU-R P.530-17 [8] provides the prediction methods for the terrestrial line-of-sight system. This prediction method is highly dependent on the specific attenuation, $\gamma$ and path reduction factor, $r$ as demonstrated in (1) and (2). Specific attenuation is calculated based on the power-law relationship between rain rate, $R$ and specific attenuation, $\gamma$ which has been included in [10].

$$
\begin{aligned}
\gamma= & k R^{\alpha} \\
r= & 1 /\left(0.477 d^{0.633} R_{0.01}^{0.073 \propto} f^{0.123}-\right. \\
& \quad 10.579(1-\exp (-0.024 d)))
\end{aligned}
$$

where the constant $k$ and $\alpha$ are the function of frequency, $f$ from 1 to $1000 \mathrm{GHz}$ with respect to horizontal and vertical polarization, $d$ is the path length and $R_{0.01}$ is the rainfall rate at $0.01 \%$ of the time. According to [8], the recommended $r$ value is 2.5 for the denominator in (2) which is less than 0.4.

The path length $d_{\text {eff }}$ as derived in (3) is one of the essential factors and needed to be considered in the interest of computing path attenuation. It is the hypothetical length along the path in which the attenuation is resulted from a point rainfall rate that occurs at any time percentage and can be determined by multiplying the actual path length, $d$ by the reduction factor, $r$ at $0.01 \%$ of time exceedance calculated from (2). The path attenuation, $A$ exceeded at $0.01 \%$ of the time can be estimated from (4).

$$
\begin{gathered}
d_{e f f}=d r_{0.01} \\
A_{0.01}=\gamma d_{e f f}
\end{gathered}
$$

Another option to predict the rain attenuation is by applying the Synthetic Storm Technique (SST) developed by Matricciani [9]. It is a physical-mathematical model that able to convert time series of rain rate into time series of rain attenuation. This model can be used to predict rain attenuation in terrestrial line-of-sight links [11] as well as in satellite links [12]. Horizontal wind speed at 700 mbar pressure level is initially estimated to convert rain rate time series into rain rate space series. By assuming that a point positioned along the $\mathrm{x}$-axis with rainfall rate, $R$ measured at the same location, the attenuation, $A$ along the path is calculated using expression (5).

$$
A\left(x_{o}\right)=k \int_{x_{0}-L / 2}^{x_{o}+L / 2} R^{\propto}(x) d x
$$

The $k$ and $\alpha$ of the rain layer should be used in (5) for terrestrial link applications. The attenuation with time is restricted through the changing of path distance along the $\mathrm{x}$-axis at a rate equal to the advection velocity, $v$ of rain cell as expressed in (6). This can also be computationally represented as the convolution between rectangular unit amplitude and width centralized at origin described in (7) and (8).

$x_{o}=v t$

$$
\begin{aligned}
& A\left(x_{o}\right)=k \int_{-\infty}^{\infty} R^{\propto}\left(x_{o}+x\right) \text { rect }\left(\frac{x}{L}\right) d x \\
& A\left(x_{o}\right)=k \int_{-\infty}^{\infty} R^{\propto}(x) \text { rect }\left(\frac{x_{o}-x}{L}\right) d x
\end{aligned}
$$

\section{DATA PROCESSING}

In this work, the rain attenuation is predicted using 3-years of 1-minute rain data collected from the year 1992 to 1994 in Kuala Lumpur, Malaysia. Both ITU-R P.530-17 and SST models are used to predict the rain attenuation. The local horizontal wind speed at the pressure level of 700 mbar is 6.2 $\mathrm{m} / \mathrm{s}$ [12]. The rainfall rate at $0.01 \%$ of the time used for the ITU-R model is $141 \mathrm{~mm} / \mathrm{hr}$ and vertically polarization is used. The $k$ and $\alpha$ coefficient values used for both prediction models at three different frequencies in this study are tabulated in Table 1. The results are compared to evaluate the impact of path length and frequency as well as the monsoon effect on the $5 \mathrm{G}$ network. Likewise, the predicted result has also compared with the rain attenuation predicted in the temperate region [13]. The effective path length is used as the actual path length particularly for path length that more than $1.8 \mathrm{~km}$.

Table 1: Coefficients $k$ and $\alpha$ values used for SST and ITU-R models at three different frequencies

\begin{tabular}{|c|c|c|c|c|}
\hline $\begin{array}{c}\text { Frequency } \\
(\text { GHz })\end{array}$ & $\boldsymbol{k}$ (SST) & $\boldsymbol{\alpha}$ (SST) & $\begin{array}{c}\boldsymbol{k} \\
(\text { ITU-R) }\end{array}$ & $\begin{array}{c}\boldsymbol{\alpha} \\
(\text { ITU-R) }\end{array}$ \\
\hline 20 & 0.089639 & 1.0154 & 0.0961 & 0.9847 \\
\hline 26 & 0.148438 & 0.9967 & 0.1669 & 0.9421 \\
\hline 30 & 0.200858 & 0.9771 & 0.2291 & 0.9129 \\
\hline
\end{tabular}


Shi Jie Seah et al., International Journal of Advanced Trends in Computer Science and Engineering, 9(1.4), 2020, 157- 162

\section{RESULT AND DISCUSSION}

Figure 2 presents the impact of path length at frequency 26 $\mathrm{GHz}$ on yearly statistics. It is clearly shown that the attenuation increases with the increasing path length. At $0.01 \%$ of the time, the attenuation at $0.2 \mathrm{~km}$ path length for $5 \mathrm{G}$ network is less than $5 \mathrm{~dB}$ whereas the attenuation reaching $38 \mathrm{~dB}$ when path length increased to $2 \mathrm{~km}$. Therefore, due to the high attenuation on longer path length, $0.2 \mathrm{~km}$ path length is proposed for the $5 \mathrm{G}$ network. Besides,
Figure $3 \mathrm{a}$ and $3 \mathrm{~b}$ show the monthly statistics of path length for $0.2 \mathrm{~km}$ and $3 \mathrm{~km}$, respectively at $28 \mathrm{GHz}$ in equatorial Malaysia. The result reveals lower rain attenuation occurs in August whereas November recorded the highest rain attenuation. The impact of monsoon season on rain attenuation is depicted in Figure 4. It is reported that inter-monsoon season occurring during April, May, October and November [14] has the highest rain attenuation while the southwest season from June to September has lower rain attenuation. The rain attenuation at

Table 2: Predicted rain attenuation at $28 \mathrm{GHz}$ for three seasons in Malaysia

\begin{tabular}{|c|c|c|c|c|c|c|c|c|c|}
\hline \multirow{3}{*}{$\begin{array}{l}\text { Percentage of time } \\
\text { exceedance }(\%)\end{array}$} & \multicolumn{9}{|c|}{ Rain attenuation (dB) } \\
\hline & \multicolumn{3}{|c|}{ Northeast } & \multicolumn{3}{|c|}{ Southwest } & \multicolumn{3}{|c|}{ Intermonsoon } \\
\hline & $0.2 \mathrm{~km}$ & $1 \mathrm{~km}$ & $2 \mathrm{~km}$ & $0.2 \mathrm{~km}$ & $1 \mathrm{~km}$ & $2 \mathrm{~km}$ & $0.2 \mathrm{~km}$ & $1 \mathrm{~km}$ & $2 \mathrm{~km}$ \\
\hline 1 & 0.179 & 0.922 & 1.748 & 0.137 & 0.711 & 1.382 & 0.274 & 1.455 & 2.766 \\
\hline 0.1 & 2.263 & 11.628 & 20.547 & 1.832 & 9.334 & 16.925 & 2.589 & 13.113 & 23.112 \\
\hline 0.01 & 4.735 & 23.842 & 41.711 & 3.532 & 17.525 & 31.551 & 4.543 & 22.631 & 39.487 \\
\hline
\end{tabular}

a different percentage of time exceedance for path length 0.2

$\mathrm{km}, 1 \mathrm{~km}$, and $2 \mathrm{~km}$ as well as different monsoon seasons are compared and summarized in Table 2.

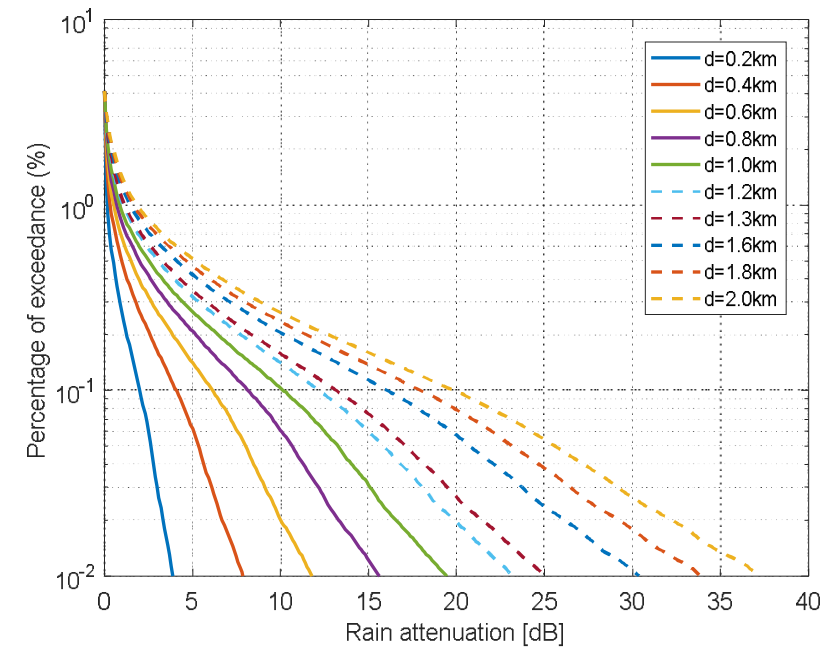

Figure 2: Impact of path length at $26 \mathrm{GHz}$

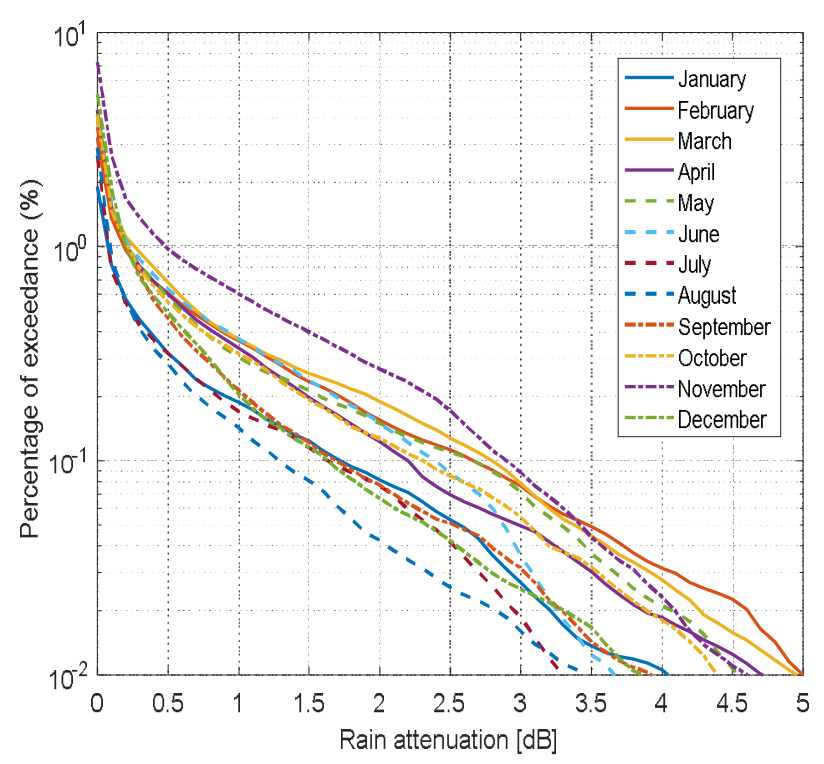

Figure 3a: Monthly statistics at $28 \mathrm{GHz}$ at $0.2 \mathrm{~km}$

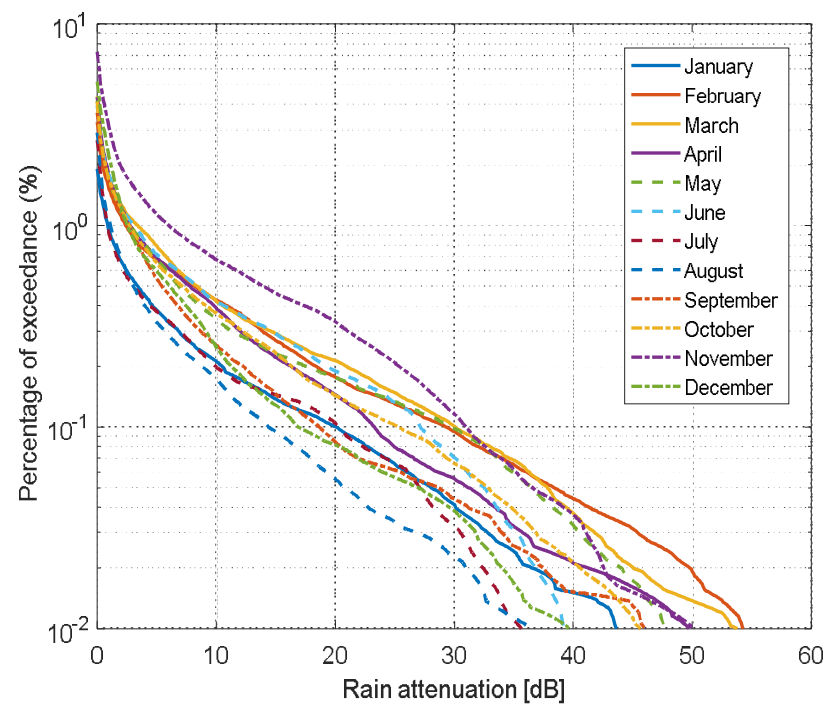

Figure 3b: Monthly statistics at $28 \mathrm{GHz}$ at $3 \mathrm{~km}$

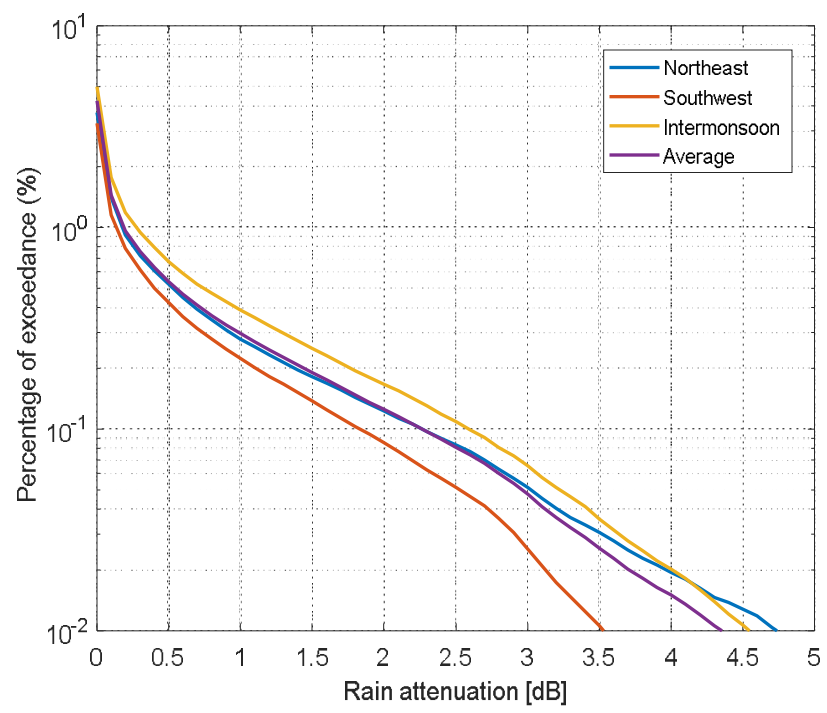

Figure 4: Impact of monsoon season at $0.2 \mathrm{~km}$ 
Shi Jie Seah et al., International Journal of Advanced Trends in Computer Science and Engineering, 9(1.4), 2020, $157-162$

Table 3: Rain attenuation at different frequencies for $1.3 \mathrm{~km}$ and $5 \mathrm{~km}$ of path length

\begin{tabular}{|c|c|c|c|c|c|}
\hline \multirow{2}{*}{$\begin{array}{l}\text { Path length } \\
\quad(\mathbf{k m})\end{array}$} & \multirow{2}{*}{$\begin{array}{l}\text { Percentage of time } \\
\text { exceedance }(\%)\end{array}$} & \multirow{2}{*}{$\begin{array}{c}\text { Prediction } \\
\text { model }\end{array}$} & \multicolumn{3}{|c|}{ Rain attenuation (dB) } \\
\hline & & & $20 \mathrm{GHz}$ & $26 \mathrm{GHz}$ & $30 \mathrm{GHz}$ \\
\hline \multirow[t]{6}{*}{1.3} & \multirow[t]{2}{*}{1} & SST & 0.725 & 1.158 & 1.509 \\
\hline & & ITU-R & 2.084 & 2.807 & 3.268 \\
\hline & \multirow[t]{2}{*}{0.1} & SST & 8.605 & 13.153 & 16.372 \\
\hline & & ITU-R & 7.379 & 10.118 & 11.896 \\
\hline & \multirow[t]{2}{*}{0.01} & SST & 16.594 & 25.074 & 30.818 \\
\hline & & ITU-R & 19.477 & 26.756 & 31.487 \\
\hline \multirow[t]{6}{*}{5.0} & \multirow[t]{2}{*}{1} & SST & 1.995 & 3.016 & 3.833 \\
\hline & & ITU-R & 4.386 & 5.870 & 6.816 \\
\hline & \multirow[t]{2}{*}{0.1} & SST & 20.046 & 29.435 & 36.012 \\
\hline & & ITU-R & 15.529 & 21.156 & 24.807 \\
\hline & \multirow[t]{2}{*}{0.01} & SST & 37.522 & 54.479 & 65.988 \\
\hline & & ITU-R & 40.990 & 55.943 & 65.660 \\
\hline
\end{tabular}

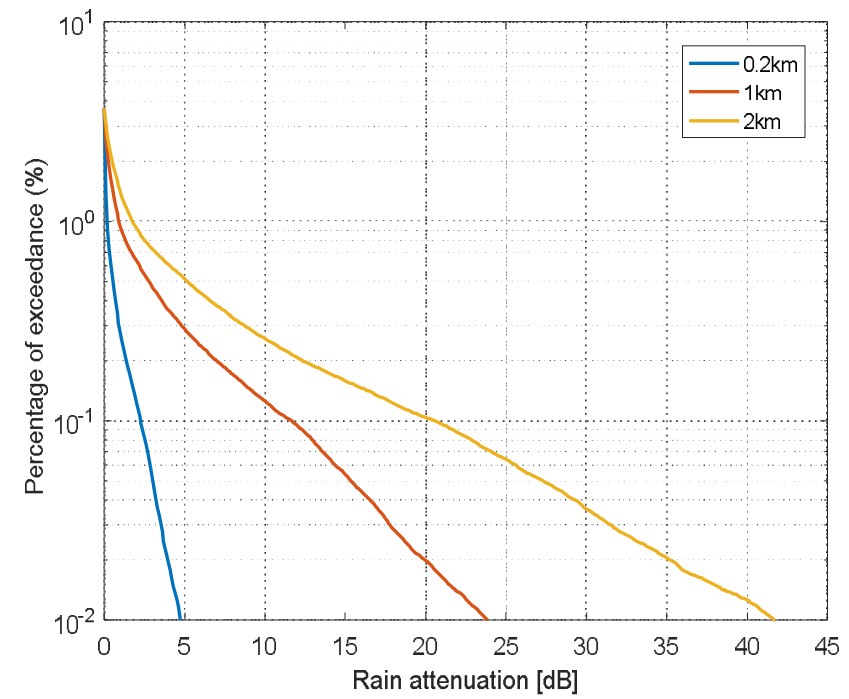

Figure 5a: Impact of path length during the northeast season at 28 $\mathrm{GHz}$

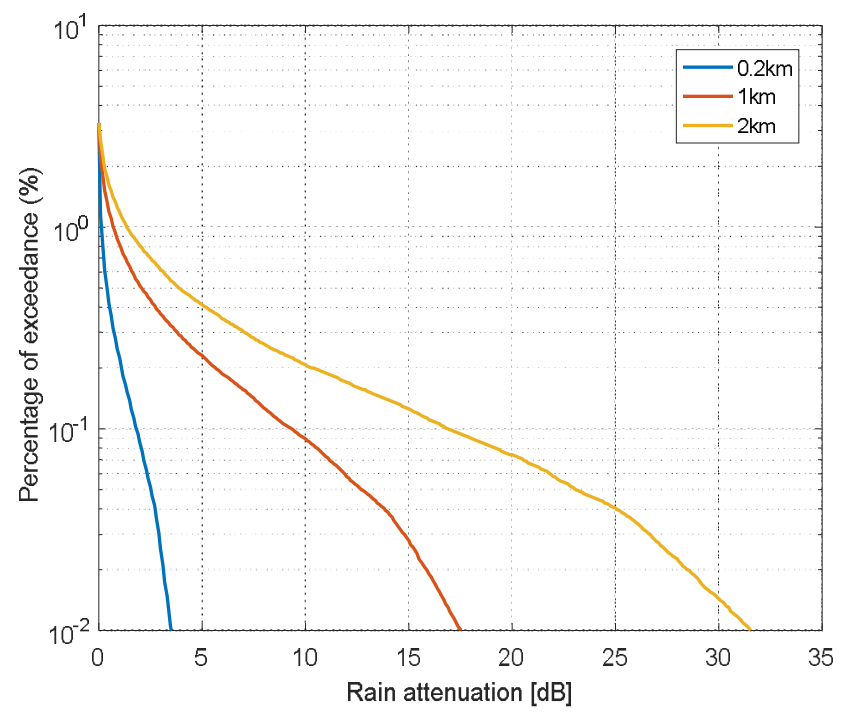

Figure 5b: Impact of path length during the southwest season at 28 $\mathrm{GHz}$

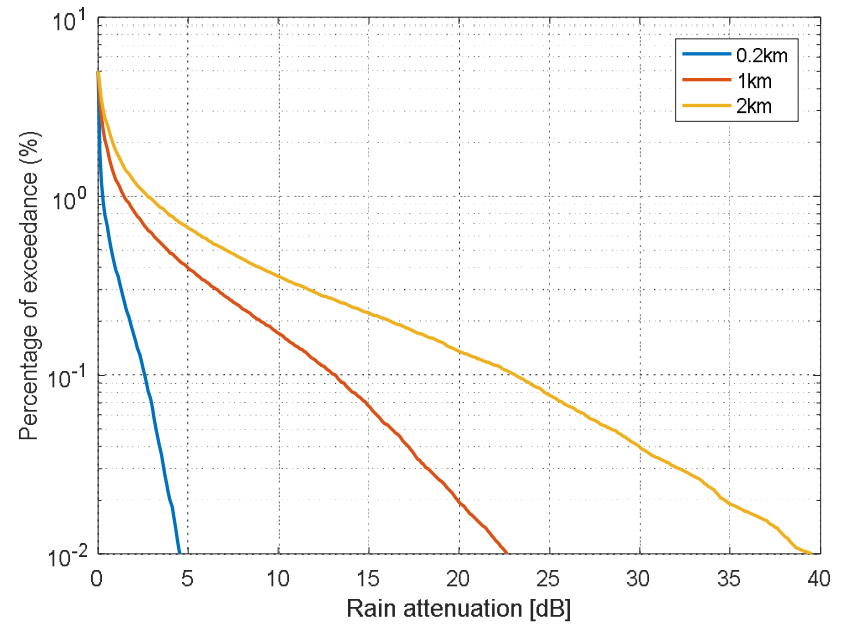

Figure 5c: Impact of path length during the intermonsoon season at $28 \mathrm{GHz}$

The impacts of path length at $28 \mathrm{GHz}$ based on northeast, southwest and inter-monsoon season are presented in Figure $5 \mathrm{a}, 5 \mathrm{~b}$ and $5 \mathrm{c}$ respectively. It can be seen that the predicted rain attenuation during the northeast season for path length $0.2 \mathrm{~km}$ is $4.735 \mathrm{~dB}$ at $0.01 \%$ time of exceedance. When the path length increase to $1 \mathrm{~km}$, the rain attenuation increase dramatically and reaching $23 \mathrm{~dB}$. It is then increased to $41 \mathrm{~dB}$ when the path length has increased to $2 \mathrm{~km}$. The rain attenuation at path length $0.2 \mathrm{~km}$ during the southwest season is $3.532 \mathrm{~dB}$ which is the lowest rain attenuation recorded among the three seasons in Malaysia at $0.01 \%$ of time exceeded. Rain attenuation during the southwest season at a path length of $1 \mathrm{~km}$ and $2 \mathrm{~km}$ are $17.525 \mathrm{~dB}$ and $31.551 \mathrm{~dB}$ respectively. During inter-monsoon season, the rain attenuation at $0.01 \%$ of the time is $4.543 \mathrm{~dB}$ at $0.2 \mathrm{~km}$ and then rising to $22.631 \mathrm{~dB}$ at $1 \mathrm{~km}$ and $39.487 \mathrm{~dB}$ at $2 \mathrm{~km}$. This proves that path length plays an important role in determining rain attenuation. Besides that, the predicted rain attenuation using SST and ITU-R models for different frequencies at $1.3 \mathrm{~km}$ path length has been evaluated and depicts in Figure 6. At $1 \%$ and $0.01 \%$, SST has lower 
attenuation as compared to the ITU-R model. However, SST has higher attenuation against the ITU-R model at $0.1 \%$ time of exceedance. Using SST model, the rain attenuation of $0.725,8.605$ and $16.594 \mathrm{~dB}$ in parallel $1.509,16.372$ and $30.818 \mathrm{~dB}$ were obtained in $1 \%, 0.1 \%$ and $0.01 \%$ of time for 20 and $30 \mathrm{GHz}$ respectively. Meanwhile, by using the ITU-R model, rain attenuation of $2.084,7.379$ and $19.477 \mathrm{~dB}$ were achieved for $20 \mathrm{GHz}$ and $3.268,11.896$ and $31.487 \mathrm{~dB}$ for 30 $\mathrm{GHz}$ at $1 \%, 0.1 \%$, and $0.01 \%$. The predicted rain attenuation for different frequencies and path lengths is compared and tabulated in Table 3.

On top of that, the predicted rain attenuation in tropical regions in Kuala Lumpur, Malaysia was also compared with the predicted rain attenuation at the temperate region in Milan, Italy [13] and is demonstrated in Figure 7. The rain attenuation is predicted for $5 \mathrm{~km}$ path length at $30 \mathrm{GHz}$ of frequency. Despite that, the rain attenuation in tropical regions is predicted using SST and ITU-R models while the prediction model used in the temperate region is MultiEXCELL [13]. The $k$ and $\alpha$ coefficient values used in these models has tabulated in Table 1 . At $1 \%$ time of occurrence, the rain attenuation predicted using the SST model in the tropical region is lower as compared to the rain attenuation predicted using the ITU-R model and in the temperate region. However, the rain attenuation predicted using the SST model is increased and higher than the rain attenuation in the temperate region as well as the ITU-R model predicted in the tropical region at both $0.1 \%$ and $0.01 \%$ time of occurrence. At $0.01 \%$, the rain attenuation in Milan is $47 \mathrm{~dB}$. In Kuala Lumpur, the rain attenuation is $65.66 \mathrm{~dB}$ when predicted using the ITU-R model and $66 \mathrm{~dB}$ for the SST model. It is obviously shown that the predicted rain attenuation in tropical regions is higher than in the temperate region. This occurrence may be due to the high rain intensities throughout the year in tropical regions. Beyond that, the rain attenuation predicted using SST is slightly higher in accordance with ITU-R model.

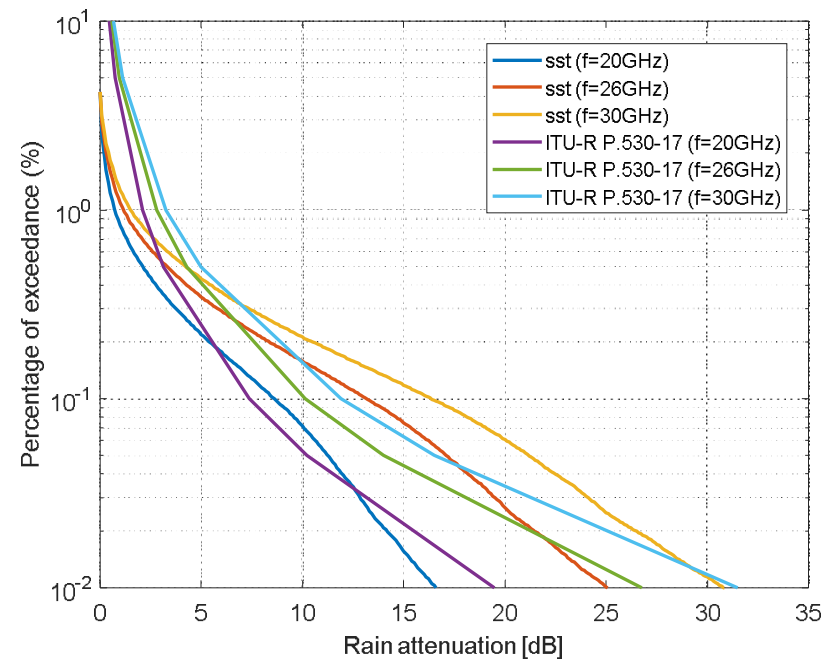

Figure 6: Predicted rain attenuation at different frequencies for 1.3 $\mathrm{km}$ path length

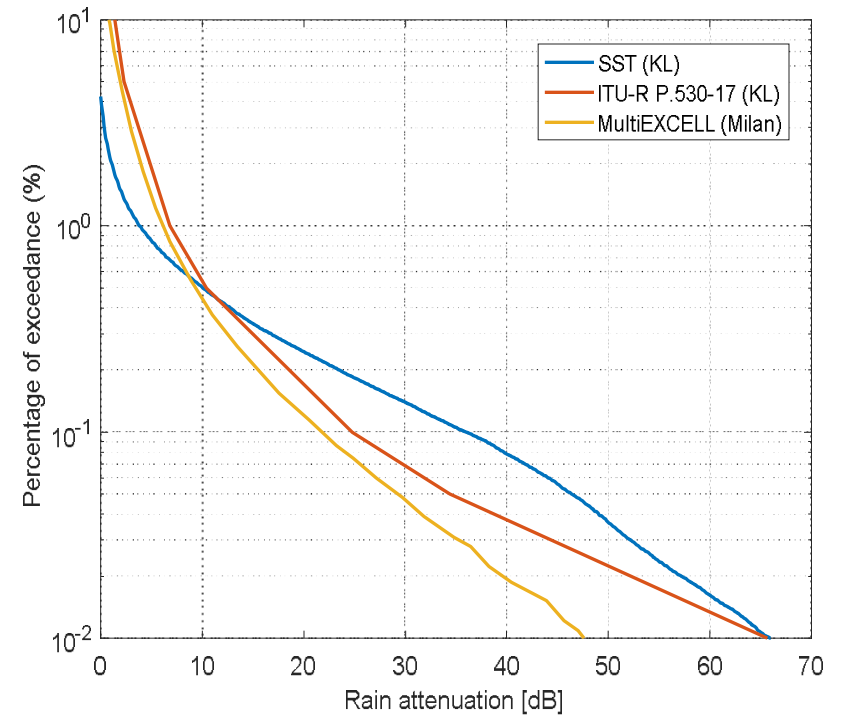

Figure 7: Comparison of predicted rain attenuation at the tropical and temperate region

\section{CONCLUSION}

Based on the presented results for the studies on the $5 \mathrm{G}$ network link, the predicted statistics of rain attenuation for $5 \mathrm{G}$ candidate frequencies are subsequently presented for short path length links. The existing rain attenuation models were used to compare the predicted results in terms of different path lengths and frequency as well as the monsoon effect. It can be clearly noticed that the monthly statistics are significantly higher than the yearly statistics. It can also be concluded that if the distance between the base station is as short as only $200 \mathrm{~m}$, the rain attenuation is lower and link performance is better. Additionally, the predicted rain attenuation using the SST model follows closely with the rain attenuation predicted by using the ITU-R model. Both prediction models can be used for the prediction of $5 \mathrm{G}$ signal attenuation. The outcomes are of great importance for the implementation of $5 \mathrm{G}$ cellular communications in heavy rain regions.

\section{ACKNOWLEDGEMENT}

Authors would like to express deeply gratitude to UTHM funded under FRGS RACER K157, "Tier 1" Vot No. H160 and $\mathrm{H} 262$.

\section{REFERENCES}

1. Andrews, J. G., Buzzi, S., Choi, W., Hanly, S. V., Lozano, A., Soong, A. C. K., and Zhang, J. C. What will 5G be?, IEEE Journal on Selected Areas in Communications, vol. 32, no. 6, pp. 1065-1082, 2014. https://doi.org/10.1109/JSAC.2014.2328098

2. Vora, M. L. J. Evolution of mobile generation technology: 1G To 5G and review of upcoming wireless technology 5G, International Journal of 
Modern Trends in Engineering and Research, vol. 2, no. 10, pp. 281-290, 2015.

3. Khdhir, R., and Belghith, A. 5G LTE-A cognitive multiclass scheduling scheme for Internet of Things, International Journal of Advanced Trends in Computer Science and Engineering, vol. 8, no. 5, pp. 2485-2491, 2019.

https://doi.org/10.30534/ijatcse/2019/94852019

4. Setyo, J., Gunawan, A., Rizki, M., and Wang, G. Challenge of $5 \mathrm{G}$ network technology for telemedicine and telesurgery, International Journal of Advanced Trends in Computer Science and Engineering, vol. 8, no. 6, pp. 3680-3683, 2019. https://doi.org/10.30534/ijatcse/2019/154862019

5. Lam, H. Y., Din, J., and Jong, S. L. Statistical and physical descriptions of raindrop size distributions in equatorial Malaysia from disdrometer observations, Advances in Meteorology, pp. 1-14, 2015.

6. Nandi, D., and Maitra, A. Study of rain attenuation effects for 5G Mm-wave cellular communication in tropical location, IET Microwaves, Antennas and Propagation, vol. 12, no. 9, pp. 1504-1507, 2018.

7. Rappaport, T. S., Sun, S., Mayzus, R., Zhao, H., Azar, Y., Wang, K., Wong, G. N., Schulz, J. K., Samimi, M., and Gutierrez, F. Millimeter wave mobile communications for $\mathbf{5 G}$ cellular: it will work!, IEEE Access, vol. 1, pp. 335-349, 2013.

8. ITU-R P.530-17. Propagation data and prediction methods required for the design of terrestrial line-of-sight systems, Recommendation ITU-R, pp. 1-24, 2017.

9. Matricciani, E. Physical-mathematical model of the dynamics of rain attenuation based on rain rate time series and a two-layer vertical structure of precipitation, Radio Science, vol. 31, no. 2, pp. 281-295, 1996.

10. ITU-R P.838-3. Specific attenuation model for rain for use in prediction methods, Recommendation $I T U-R$, pp. 1-8, 2005.

11. Mandeep, J. S. Rain attenuation statistics over a terrestrial link at $32.6 \mathrm{GHz}$ at Malaysia, IET Microwaves, Antennas \& Propagation, vol. 3, no. 7, pp. 1086-1093, 2009.

12. Jong, S. L., Riva, C., D’Amico, M., Lam, H. Y., Yunus, M. M., and Din, J. Performance of synthetic storm technique in estimating fade dynamics in equatorial Malaysia, International Journal of Satellite Communications and Networking, vol. 36, no. 5, pp. 416-426, 2018.

13. Ghiani, R., Luini, L., and Fanti, A. A physically based rain attenuation model for terrestrial links, Radio Science, vol. 52, no. 8, 972-980, 2017. https://doi.org/10.1002/2017RS006320

14. Jong, S. L., Lam, H. Y., Amico, M. D., and Din, J. Analysis of precipitation characteristics over Southern Peninsular Malaysia for satellite propagation application, in 2016 URSI Asia-Pacific
Radio Science Conference (URSI AP-RASC), 2016, pp. 1729-1732. 